\title{
DISTRIBUIÇÃO DE MACRÓFITAS AQUÁTICAS NUMA LAGOA NA FAZENDA NHUMIRIM, NHECOLÂNDIA, PANTANAL, MS
}

\author{
Vali J. Pott (1) \\ Norma C. Bueno $(2,3)$ \\ Rosana A. C. Pereira $(2,3)$ \\ Suzana M. De Salis (4) \\ Neuza L. Vieira (3)
}

\begin{abstract}
RESUMO - A Nhecolândia, uma sub-região arenosa do Pantanal, possui muitas lagoas ("baías") rasas e subcirculares. Levantou-se, em outubro de 1988, através de duas transecções, a vegetação aquática de uma lagoa permanente, denominada "Baía da Sanguessuga", com $250 \mathrm{~m}$ de diâm. e até $1,2 \mathrm{~m}$ prof. (época seca), na fazenda Nhumirim $\left(18^{\circ} 59^{\prime} \mathrm{S}\right.$ e $56^{\circ} 39^{\prime} \mathrm{W}$, e alt $\left.90 \mathrm{~m}\right)$. As plantas foram coletadas e depositadas nos Herbários CPAP e COR. São apresentadas lista de 37 plantas ocorrentes, suas formas biológicas, e gráficos de frequência das principais espécies. As espécies mais freqüentes são: Utricularia spp., Salvinia auriculata, Cabomba pyauhyensis, Hydrocleis nymphoides, Cyperus cf.polystachyos, Eleocharis spp., Pontederia cordata, Nymphaea amazonum e Echinodorus spp. Observou-se zonação na distribuição das principais espécies, explicada pela relação entre profundidade e forma biológica das plantas.
\end{abstract}

Palavras-chave: Hidrófitas, terras úmidas, ecologia vegetal, vegetação.

\begin{abstract}
Nhecolandia, a sandy sub-region of the Pantanal, has many shalow and subcircular lakes. In october 1988 two transects were established to survey the aquatic vegetation of a permanent pond, named "Baia da Sanguessuga", $250 \mathrm{~m}$ diameter and $1,2 \mathrm{~m}$ deep (dry season), at Nhumirim farm $\left(18^{\circ} 59^{\prime} \mathrm{S}, 56^{\circ} 39^{\prime} \mathrm{W}\right.$, and 90 $\mathrm{m}$ alt.). Plants were colected and kept at CPAP and COR Herbaria. A list of 37 plants, their life forms and frequency graphs are presented. The most frequent species are: Utricularia spp., Salvinia auriculata, Cabomba pyauhyensis, Hydrocleis nymphoides, Cyperus cf. polystachyos, Eleocharis spp., Pontederia cordata, Nymphaea amazonum and Echinodorus spp. There is a relation between depth and life form, and a zonation on the distribution of the most important species.
\end{abstract}

Key words: Hydrophytes, aquatic plants, wetland, plant ecology, vegetation.

(1) Bióloga, CEUC/UFMS, Corumbá, MS .

(2) Bolsista do CNPq, CPAP/EMBRAPA.

(3) Acadêmica de Ciências Biológicas, CEUC/UFMS.

(4) Bióloga, CPAP/EMBRAPA, Caixa Postal 109, Corumbá, MS, CEP 79300. 


\section{Introduçāo}

O Pantanal apresenta uma heterogeneidade interna marcada pela relação flora-níveis de inundação, havendo diversos "pantanais" com características próprias (Adámoli, 1982).

A sub-região da Nhecolândia, com $24.762 \mathrm{~km}^{2}(17,8 \%$ da área do Pantanal)(Adámoli, 1982), formada por sedimentos arenosos do rio Taquari, caracteriza-se pela riqueza de corpos d'água subcirculares, lagoas, pelo que é uma área favorável a plantas aquáticas e uliginosas (Pott et al. 1986a). Há dois tipos principais de lagoas: a "baía", de água doce, podendo ser temporária ou permanente, e a "salina", alcalina. O caráter temporário ou permanente depende da profundidade, da drenagem e do ciclo climático. Em Wilhelmy (1957) encontra-se uma boa descrição de lagoas. Mourão (1989) fez uma estudo limnológico comparativo de lagoas na fazenda Nhumirim.

A bibliografia botânica sobre o Pantanal é escassa, por ser uma região floristicamente pouco inventariada (Prance \& Schaller, 1982). Hoehne (1923, 1948) foi um dos que mais escreveu sobre a flora pantaneira, principalmente quanto à aquática, tendo citado muitas espécies hidrófilas e higrófilas, sem menção a solo ou sub-região. Joly (1970) descreveu brevemente a vegetação aquática do Pantanal, podendo-se deduzir que se tratavam de área argilosas. Lorenzi (1982) assinala várias plantas aquáticas para a região. Da Silva (1989) cita a importância das macrófitas aquáticas no Pantanal. São escassas as informações sobre plantas de lagoas e de área alagadas do Pantanal arenoso, havendo duas listas florísticas preliminares, uma para Nhecolândia e Paiaguás (Pott $e t$ al. 1986a) e outra para a fazenda Nhumirim (Pott et al. 1986b).

Pott et al. (1986a) mencionam que há nítida zonação na distribuição das plantas lacustres do Pantanal arenoso, sem quantificá-la. Com o objetivo de observar variedade, distribuição, frequência e relação entre profundidade e forma biológica das principais espécies vegetais vasculares, foi realizado o levantamento da vegetação aquática de uma lagoa considerada fisionomicamente representativa da Nhecolândia.

\section{Material e Métodos}

O trabalho foi realizado na fazenda Nhumirim, da EMBRAPA/CPAP, de 4.310 ha, apresentando $c .100$ lagoas durante o período de inundação (Mourão et al. 1988). O levantamento da vegetação aquática foi feito numa lagoa considerada permanente, denominada "Baía da Sanguessuga", de no 49 (Figura 1), com c. $250 \mathrm{~m}$ diâm. e até $1,2 \mathrm{~m}$ prof. Em outubro, final da estação seca, o nível limnimétrico está mais baixo.

Segundo Mourão et al. (1988), em dezembro de 1985, a água apresentou $\mathrm{pH}=6,1$, condutividade elétrica $=116 \mu \mathrm{Scm}^{-2}$, e oxigênio dissolvido $=0,87$ $\mathrm{mg} / \mathrm{l}$. Nas cheias maiores há coalescência com lagoas contíguas, semelhantes.

O método utilizado foi o de transecção contínua, perpendicular à borda da lagoa, até o centro. Foram feitas duas transecções, com distância inicial de 64,5 
m entre si, culminando no centro aproximado da lagoa (Figura 2). Os pontos nas transecções foram marcados de $0,5 \mathrm{em} 0,5 \mathrm{~m}$, utilizando-se trena e barco. A transecção I mediu $104,5 \mathrm{~m}$, sendo marcados 209 pontos, e a transecção II, $125,0 \mathrm{~m}$, com 250 pontos. $\mathrm{O}$ início das transecções na parte úmida, a $6 \mathrm{~m}$ da borda da água. Em cada ponto coletaram-se e registraram-se todas as espécies que tocaram a régua, observando-se também a profundidade da água e a forma biológica das espécies. As duas transecções foram somadas, por serem semelhantes em ocorrência e forma de vida das plantas.

O material coletado, prensado e secado em estufa, foi incorporado aos Herbários CPAP (EMBRAPA, Centro de Pesquisa Agropecuária do Pantanal) e COR (UFMS-CEUC). As espécies foram identificadas através de chaves analíticas e monografias como Hoehne (1948), Cook (1974) e Fasset (1966), e por comparação com exsicatas do Herbário CPAP.

A conceituação de "macrófitos aquáticos", segundo Cook (1974) e Fasset (1966), "lato sensu", engloba todas as plantas cujas partes fotossinteticamente ativas estão permanentemente, ou por alguns meses, submersas ou flutuantes e sejam visíveis a olho nu (CHAROPHYTA, BRYOPHYTA, PTERIDOPHYTA e SPERMATOPHYTA). As sete formas biológicas (Figura 3) são baseadas em Irgang et al. (1984) e Pedralli et al. (1985): submersas fixa = SF; submersas livre $=\mathrm{SL}$; flutuante fixa $=\mathrm{FF}$; flutuante livre $=\mathrm{FL}$; emergente $=\mathrm{E}$; anfíbia $=\mathrm{A} ;$ epífita $=\mathrm{EP}$.

Considera-se freqüência absoluta (FA) o percentual de amostras em que ocorre dada espécie, e freqüência relativa (FR) a percentagem da FA da espécie em relação à soma das FA de todas as espécies. Para avaliar a relação entre profundidade da água e a ocorrência das espécies, utilizou-se o teste $\mathrm{X}^{2}$.

\section{Resultados e Discussōes}

Foram encontradas 23 macrófitas, além de 14 fora das transecções, arroladas na Tabela 1 por ordem alfabética de família e nome científico, com a forma de vida, ocorrência e as respectivas freqüências absoluta e relativa.

Não foram encontradas algas macroscópicas, ocorrentes em lagoas alcalinas ("salinas") (Pott et al. 1986a).

A Figura 4 dá a freqüência relativa das principais espécies encontradas na lagoa, por transecção, sendo Utricularia sp.(1) e Salvinia auriculata as mais freqüentes. A representatividade das famílias ocorrentes na lagoa está demonstrada na Figura 5, destacando-se Lentibulariaceae com $1 / 3$ da freqüência relativa.

A ocorrência das espécies por faixa de profundidade é apresentada na Tabela 2 . Observou-se que a borda úmida apresenta mais espécies anfíbias e emergentes, como Bacopa spp., Echinodorus tenellus, Eleocharis sp.(2) Paspalidium paludivagum e Pontederia cordata var. lancifolia.

A Figura 6 mostra que o número de espécies é maior na profundidade mais rasa $(0-50 \mathrm{~cm})$, onde estão as emergentes e anfíbias. É a parte mais pertubada, por pastejo e pisoteio do gado. Henrique et al. (1988) também observa- 
ram maior riqueza de espécies na margem do lago e citam pastoreio como um fator determinante.

Observou-se que, à medida que baixa o nível da lagoa, a vegetação aquática marginal acompanha o recuo da água através de sucessão de espécies. Por exemplo, Salvinia foi registrada até fora da água, mas já senescente (e com esporocarpos). Pontederia cordata var. lancifolia forma um cinturão da margem até $40 \mathrm{~cm}$ de profundidade, sendo o exemplo mais evidente de zonação concêntrica.

Nymphaea amazonum parece preferir as profundidades de $0-50 \mathrm{~cm} \mathrm{e}$ acima de $100 \mathrm{~cm}$, pois não foi encontrada entre 50 e $100 \mathrm{~cm}$, distribuição para a qual não se tem explicação. Hydrocleis nymphoides, ainda que geralmente associada a $N$. amazonum, ocorreu em todas as profundidades. A submersa Utricularia sp. ocupa grande área dentro da lagoa, mesmo em faixa de ocorrência de Salvinia auriculata, provavelmente por não necessitar de muita luz, como carnívora. Ambas ocorrem em todas as profundidades. Por outro lado, Cabomba pyauhyensis ocorre na parte mais profunda associada a Utricularia sp., numa faixa de menor frequência de $S$. auriculata. Essas espécies submersas apresentam coloração parda pela grande deposição de material orgânico e perifiton. $\mathrm{Na}$ seqüência típica as comunidades submersas estão nas águas mais profundas, mas também podem ocorrer nas rasas (Sculthorpe 1967), tendo ambas situações sido encontradas nesta lagoa.

Eleocharis sp.(1) Utricularia gibba e Cyperus cf. polystachyos ocorreram associadas a $S$. auriculata como epífitas (Fig. 7). A forma "epífita" para aquática foi descrita por Tur em 1965 (Pedralli, 1988), e, embora não sendo epífita "scrictu sensu", o termo está etimologicamente correto, porque essas plantas usam outras aquáticas como suporte. Da Silva (informção pessoal) prefere o termo ancorada para $U$. gibba.

Echinodorus paniculatus, além da borda, também ocorre no centro da lagoa, onde há uma pequena elevação, vindo ao encontro do que afirma Sculthorpe (1967), que emergentes podem ocorrer em bancos em águas permanentemente profundas. Supõe-se que esta espécie, por ser rizomatosa, resista à seca, e sobreviva à cheia por ser emergente.

Pelo teste $\mathrm{X}^{2}$, a relação entre profundidade e ocorrência foi semelhante ( $\mathrm{p}$ $>0,05)$ para Cyperus cf. polystachyos e $U$. gibba; para todas as outras formas de vida testadas, $S$. auriculata x Utricularia sp., $S$. auriculata x $C$. pyauhyensis, $S$. auriculata x $C$. cf. polystachyos, $S$. auriculata $\times$ Eleocharis sp.(1), $H$. nymphoides $\mathrm{x} N$. amazonum, Utricularia sp. x C. pyauhyensis, e Eleocharus sp.(1) $\times U$. gibba $\times$. polystachyos, houve diferença significativa $(\mathrm{p}<0,05)$ quanto à relação entre profundidade da água e ocorrência das espécies.

As plantas na lagoa vivem agrupadas de acordo com a profundidade da água e forma de vida, o que está de acordo com a caracterização que Sculthorpe (1967) faz para vegetação aquática.

A ausência de grande número de outras espécies aquáticas na lagoa pode estar relacionada a tipo de solo, $\mathrm{pH}$ da água, nutrientes, ambiente lêntico, e variação temporal da lâmina d'água (período de seca e cheia). O caráter permane- 
te da lagoa é relativo ao período climático atual, pois, conforme Mourão (1989), essas lagoas chegaram a secar durante ciclos plurianuais hipohídricos.

Conclui-se que existe zonação na distribuição das plantas nas faixas da borda da lagoa em função da profundidade da água. Na borda a zonação é mais marcada porque, próximo à interface solo emerso/água, pequenas diferenças de profundidade devem representar grandes variações microecológicas para as plantas.

Este estudo apenas descreve a vegetação na estação seca; para conhecer sua dinâmica estacional dever-se-ia fazer o acompanhamento dessas comunidades ao longo do ano, o que também poderia esclarecer um possível confundimento entre efeito da profundidade com o da variação da lâmina d'água num dado ponto.

\section{Agradecimentos}

À Bióloga Iria H. Ishii, pela revisão crítica; aos pesquisadores Agostinho C. Catella, Maria Cristina M. Mazza, Francisco Y. P. Zimmermann por sugestões e apoio estatístico; ao Técnico Carlos César F. Tavares, pela ajuda no campo; ao CPAP/EMBRAPA, por hospedagem e transporte.

\section{Referências Bibliográficas}

ADÁMOLI, J. 1982. O Pantanal e suas relações fitogeográficas com os cerrados. Discussão sobre o conceito "complexo do Pantanal". In: Congresso Nacional de Botânica, 32. Teresina, 1981. Anais... Teresina, Sociedade Botânica do Brasil. p. 109-119. 109-119.

COOK, C. D. K. 1974, Water plants of the world. The Hague, W. Jung. 561p.

DA SILVA, C. J. Função das macrófitas aquáticas nas áreas alagadas no Pantanal Matogrossense, In: Congresso Nacional de Botânica, 40, Cuiabá, 1989. Resumos...,'Curabá Sociedade Botânica do Brasil, p. 640.

FASSET, N. C. 1966. A manual of aquatic plants. Madison, Univ. Wisconsin. 405p.

HENRIQUES, R. P. B.; ARAÚJO, D. S. D.; ESTEVES, F. A. \& FRANCO, A. C. 1988. Análise preliminar das comunidades de macrófitas aquáticas da Lagoa Cabiunas, Rio de Janeiro, Brasil. Acta. Limnol. Brasil., 2: 783-802.

HOEHNE, F. C. 1923. Phytophyononomia do Estado de Matto Grosso e ligeiras notas a respeito da composição e distribuição da sua flora. São Paulo, Melhoramentos, 104p.

HOEHNE, F. C. 1948. Plantas aquáticas. São Paulo, Instituto de Botânica, 167p. il. (reimpressâo, 1979).

IRGANG, B. E.; PEDRALLI, G. \& WAECHTER, J. L. 1984. Macrófitos aquáticos da Estação Ecológica do Taim, Rio Grande do Sul, Brasil. Roessleria 6(1): 395-404.

JOLY, A. B. 1970. Conheça a vegetação brasileira. São Paulo, USP, p.137-148.

LORENZI, H. 1982. Plantas daninhas do Brasil: terrestres, aquáticas, parasitas, tóxicas e medicinais. Nova Odessa, H. Lorenzi, 425p.

MOURÃO, G. de M. 1989. Estudo limnológico comparativo de três lagoas (duas "baías" e uma "salina") na fazenda Nhumirim, Pantanal da Nhecolândia. São Carlos, UFSCar. Dissertação de mestrado.

MOURĀO. G. de M.; ISHII, I. H., CAMPOS, Z. M. da S. 1988. Alguns fatores limnoló- 
gicos relacionados com a ictiofauna de Baías e Salinas do Pantanal da Nhecolândia, Mato Grosso do Sul, Brasil. Acta Limnológica Brasileira 11: 181-198.

PEDRALLI, G.; IRGANG, B. E.; PEREIRA, C. P. 1985. Macrófitos aquáticos do Município de Rio Grande. Rio Grande do Sul. Brasil. Revista AGROS 2O(1, 2, 3 E 4): 45-52.

PEDRALLI, G. 1988. Macrófitos aquáticos: as plantas fiscais. Ciência Hoje, 7(41): 76.

POTT, V. J.; POTT, A.; RATTER, J. A. \& VALLS, J. M. F. 1986a. Flora da fazenda Nhumirim, Nhecolândia Pantanal. Relação preliminar. Corumbá, EMBRAPA/CPAP. (Pesquisa em Andamento, 5).

POTT, V. J.; REGO, S. C. A. \& POTT, A. 1986b. Plantas Uliginosas e aquáticas do Pantanal Arenoso. Corumbá. EMBRAPA/CPAP, 13p. (Pesquisa em andamento. 6).

PRANCE, G. T. \& SCHALLER, G. B. 1982. Preliminary study of some vegetation types of the Pantanal, Mato Grosso, Brasil. Brittonia 34: 288-251.

SCULTHORPE, C. D. 1967. The biology of aquatic vascular plants. London. Arnold, 610 p.

WILHELMY, H. 1957. Das grosse Pantanal in Mato Grosso. In: DEUSTSCHER GEOGRAPHENTAG, Wuerzburg, 1957. Tagungsberichte und Wiss. Abhabdlungen. Wiesbaden, Franz Steiner, p.45-71. 


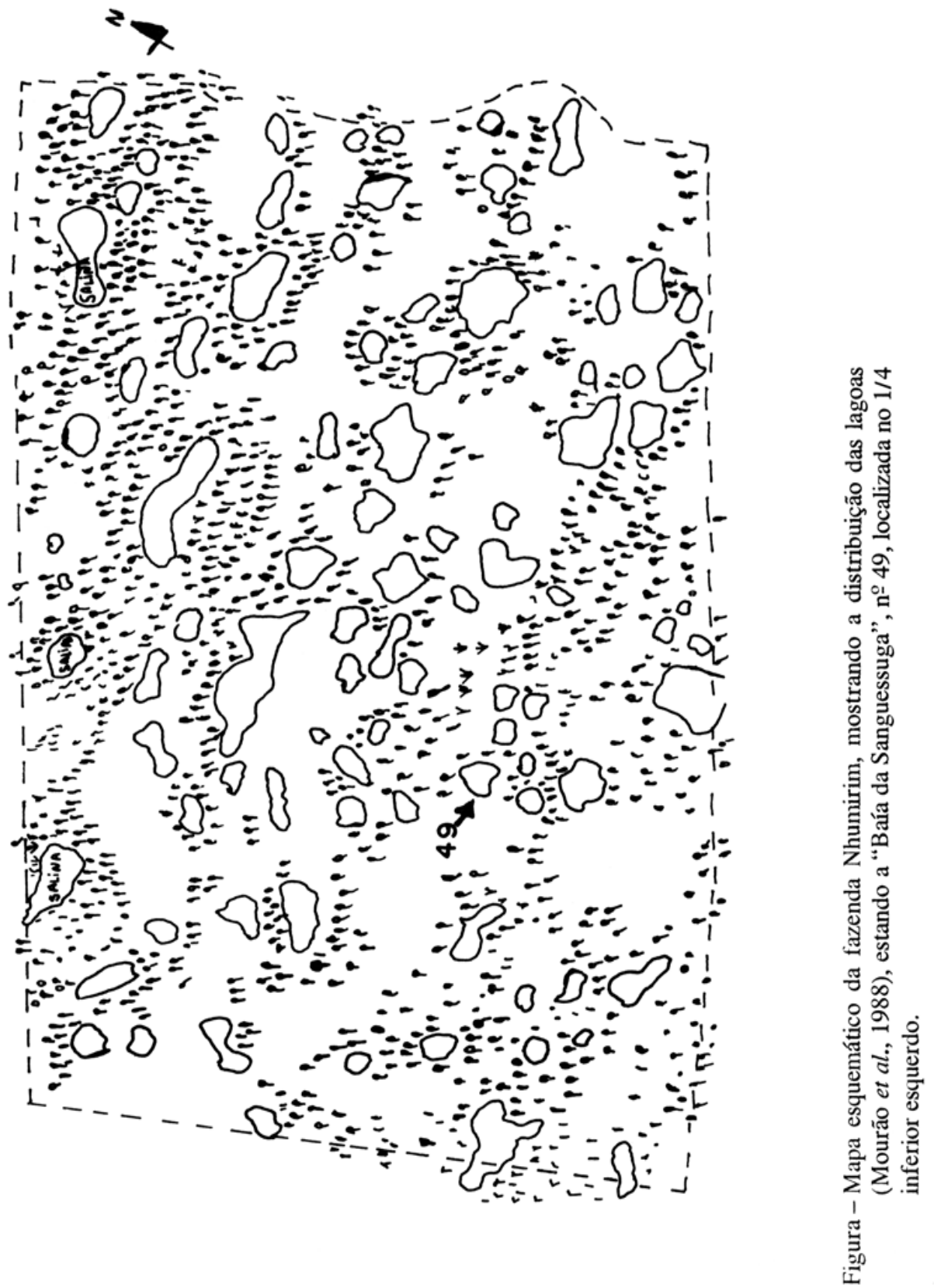




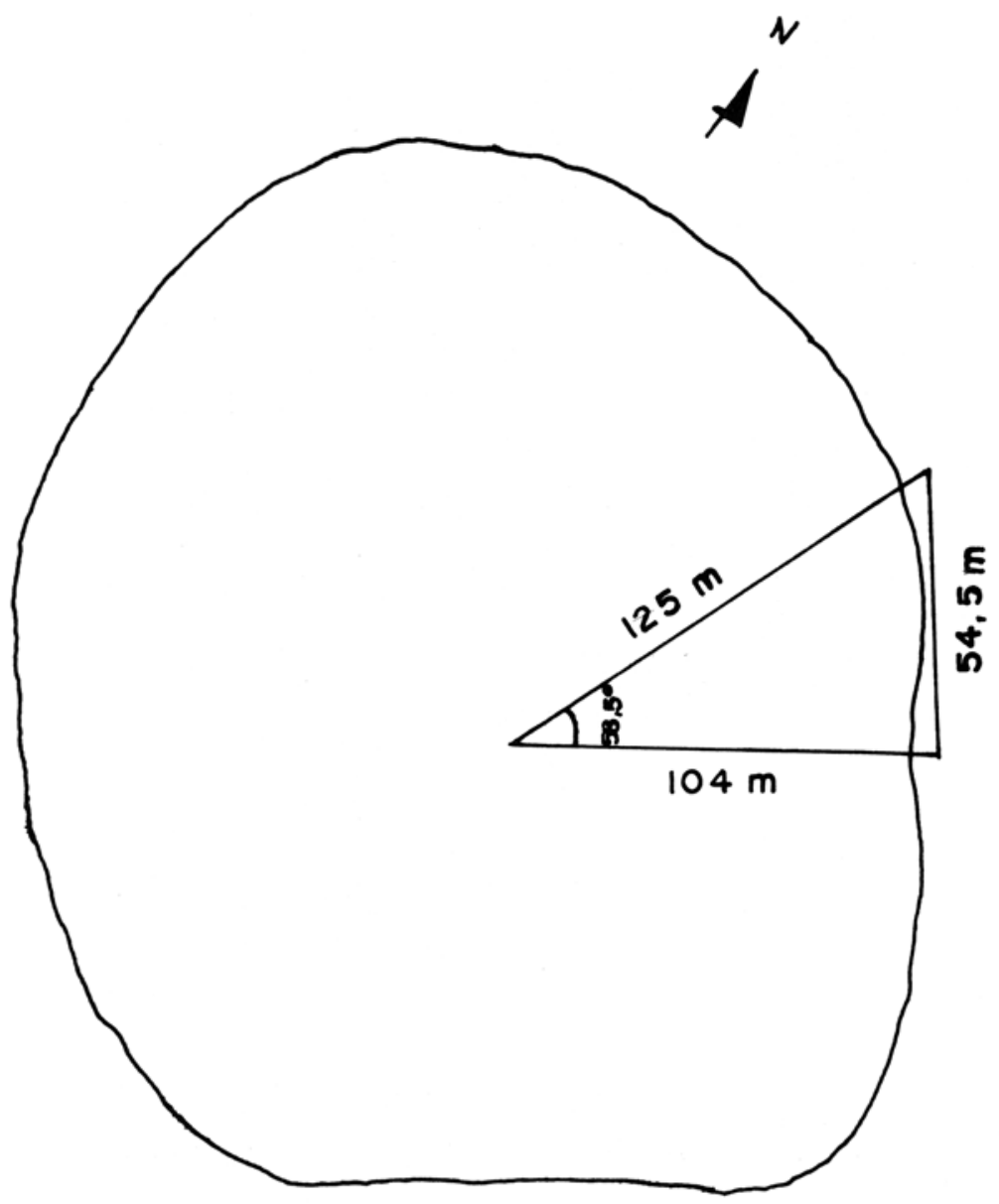

Figura 2 - Representação dos transectos na "Baía do Sanguessuga”, fazenda Nhumirim, Nhecolândia, Pantanal, out/ 1988. 

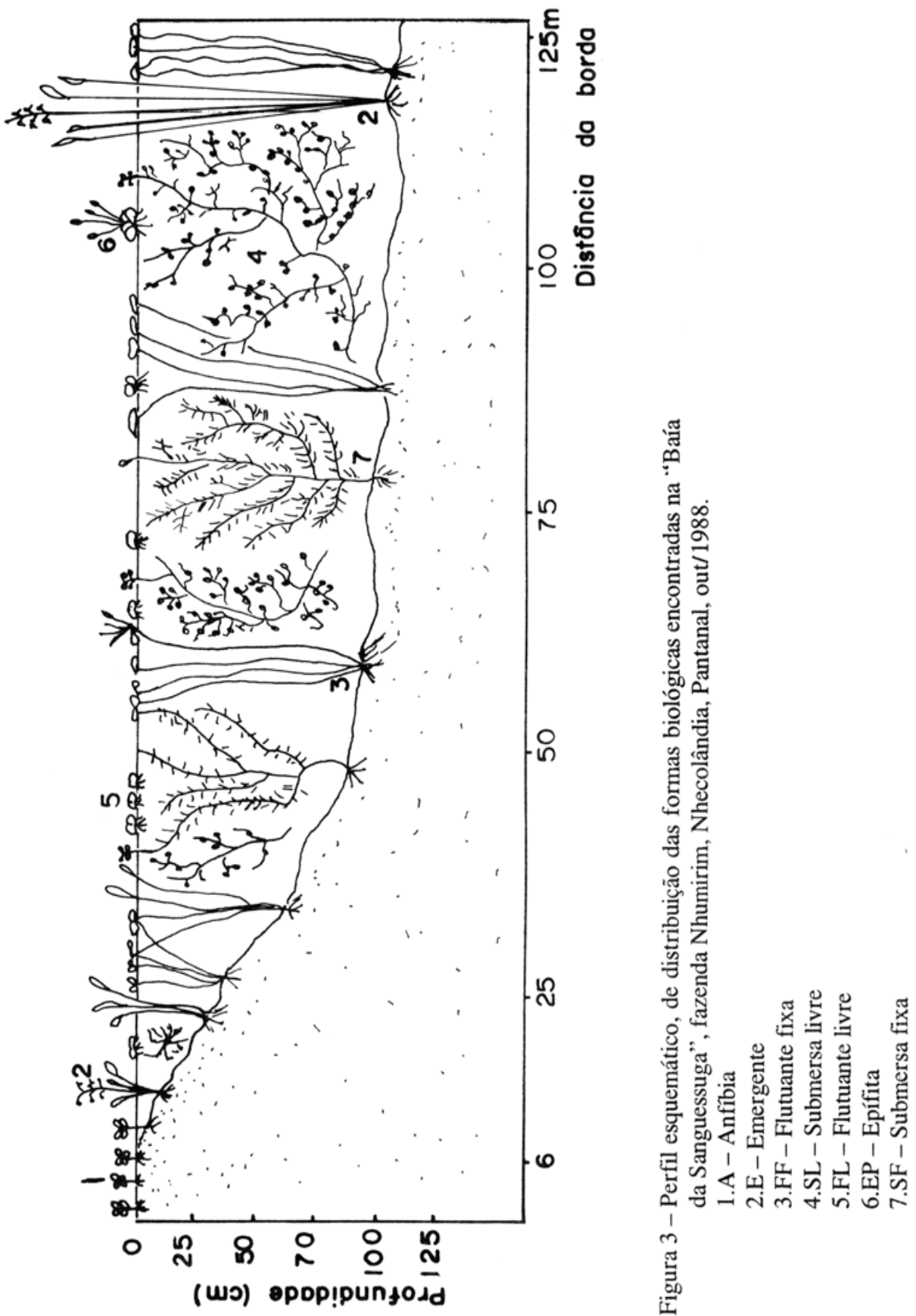


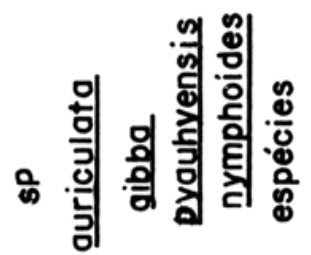

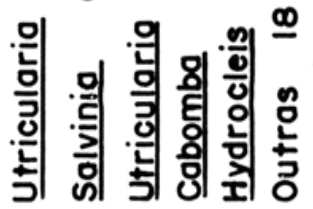

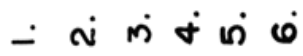

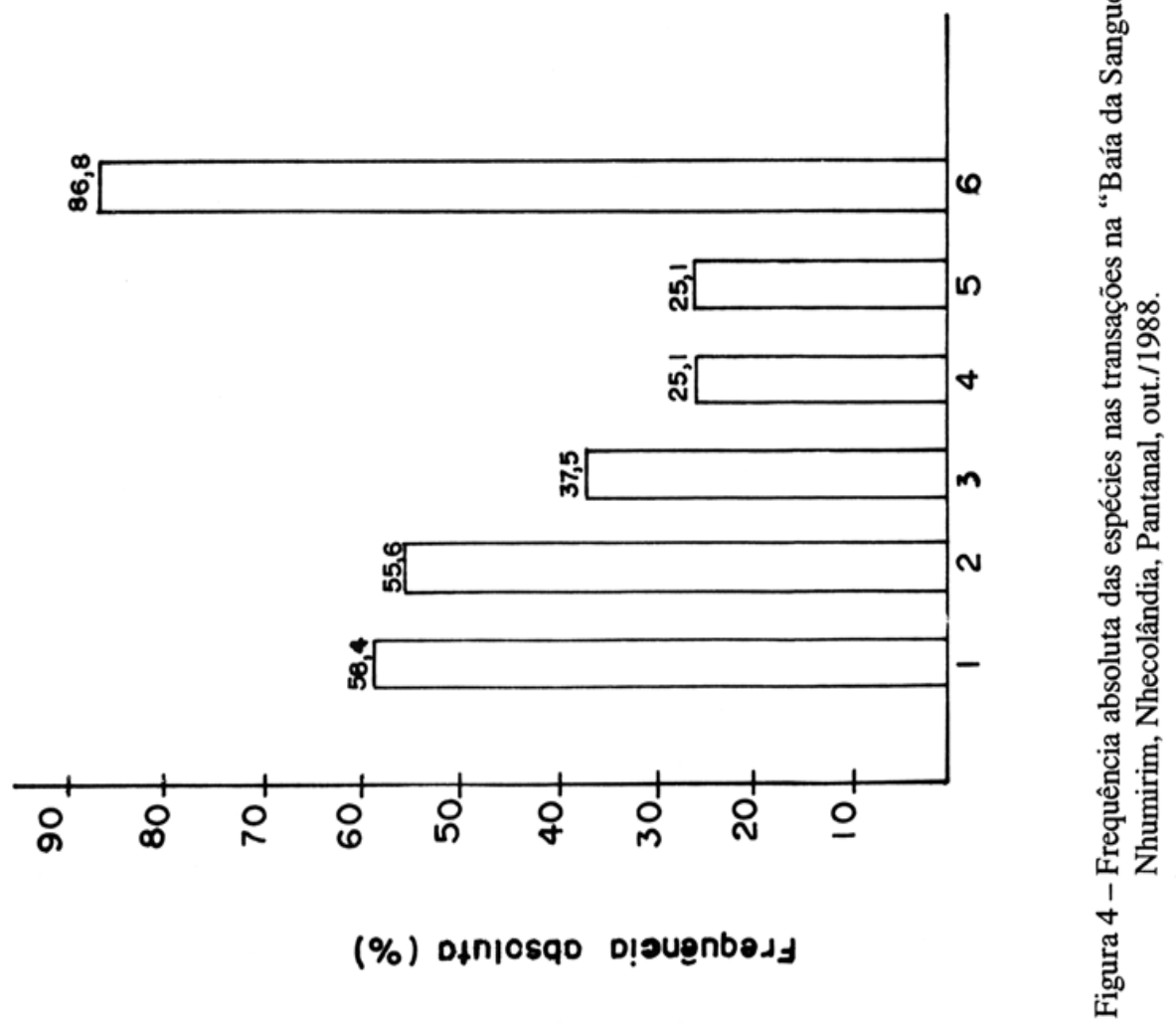



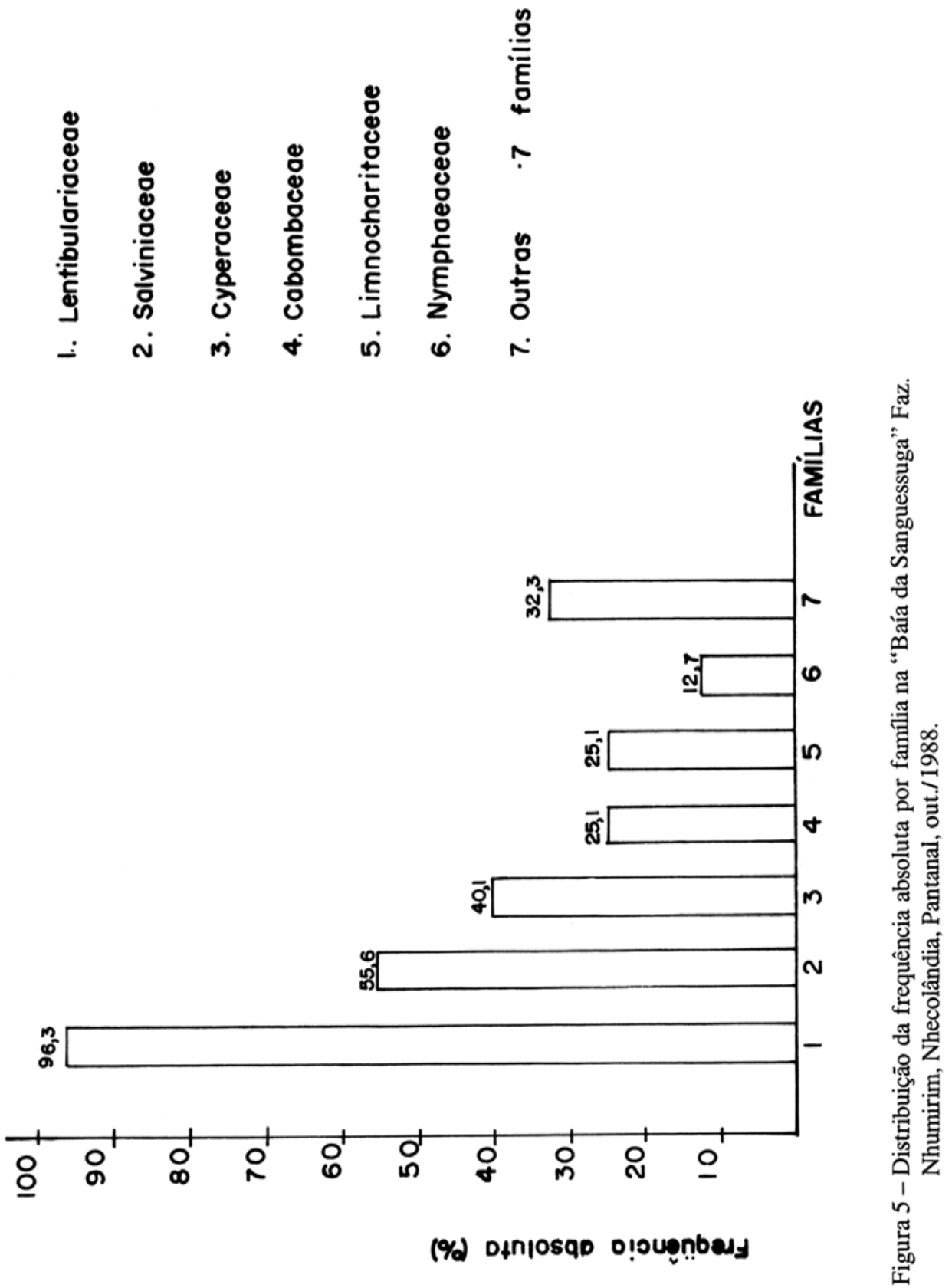


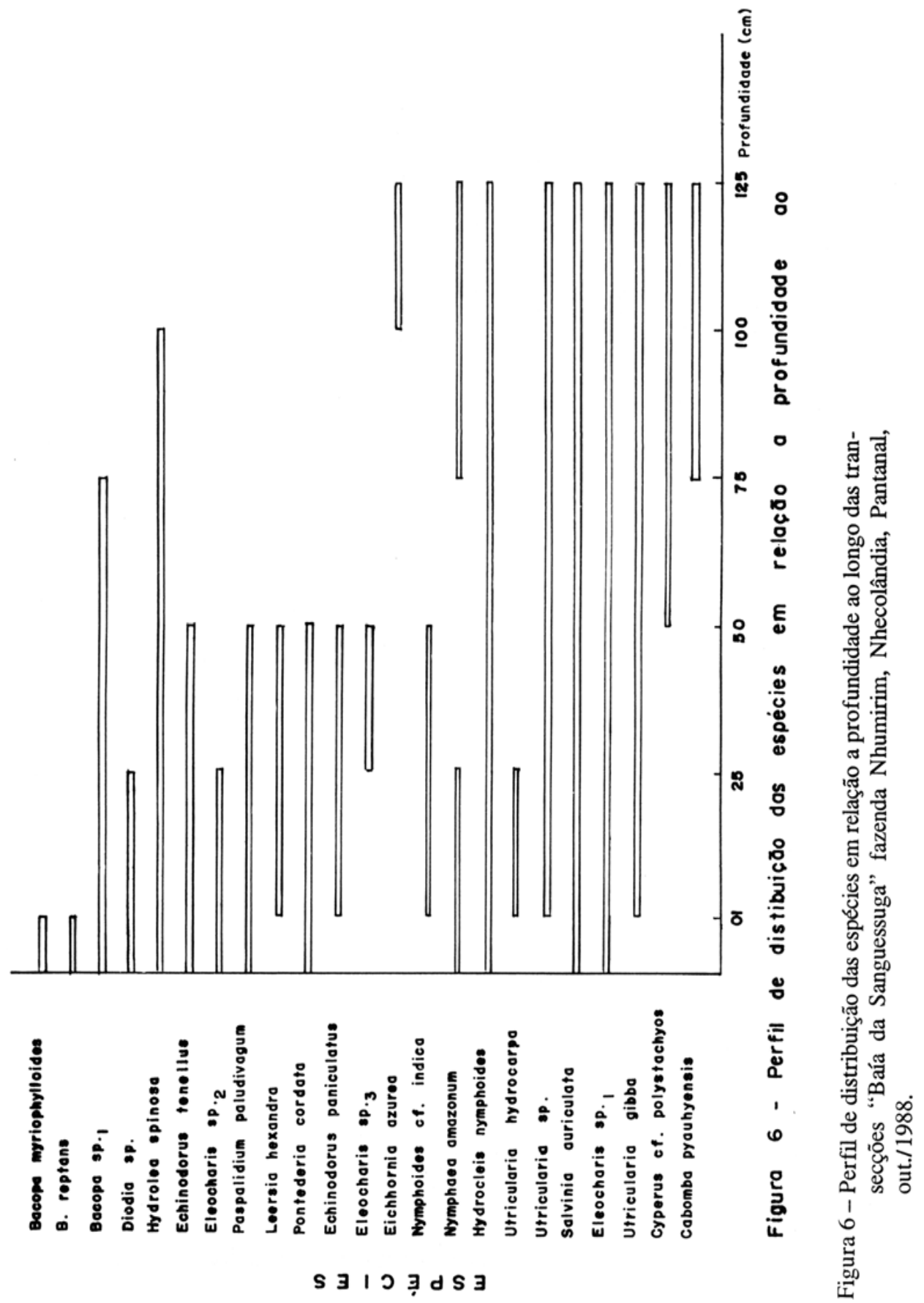



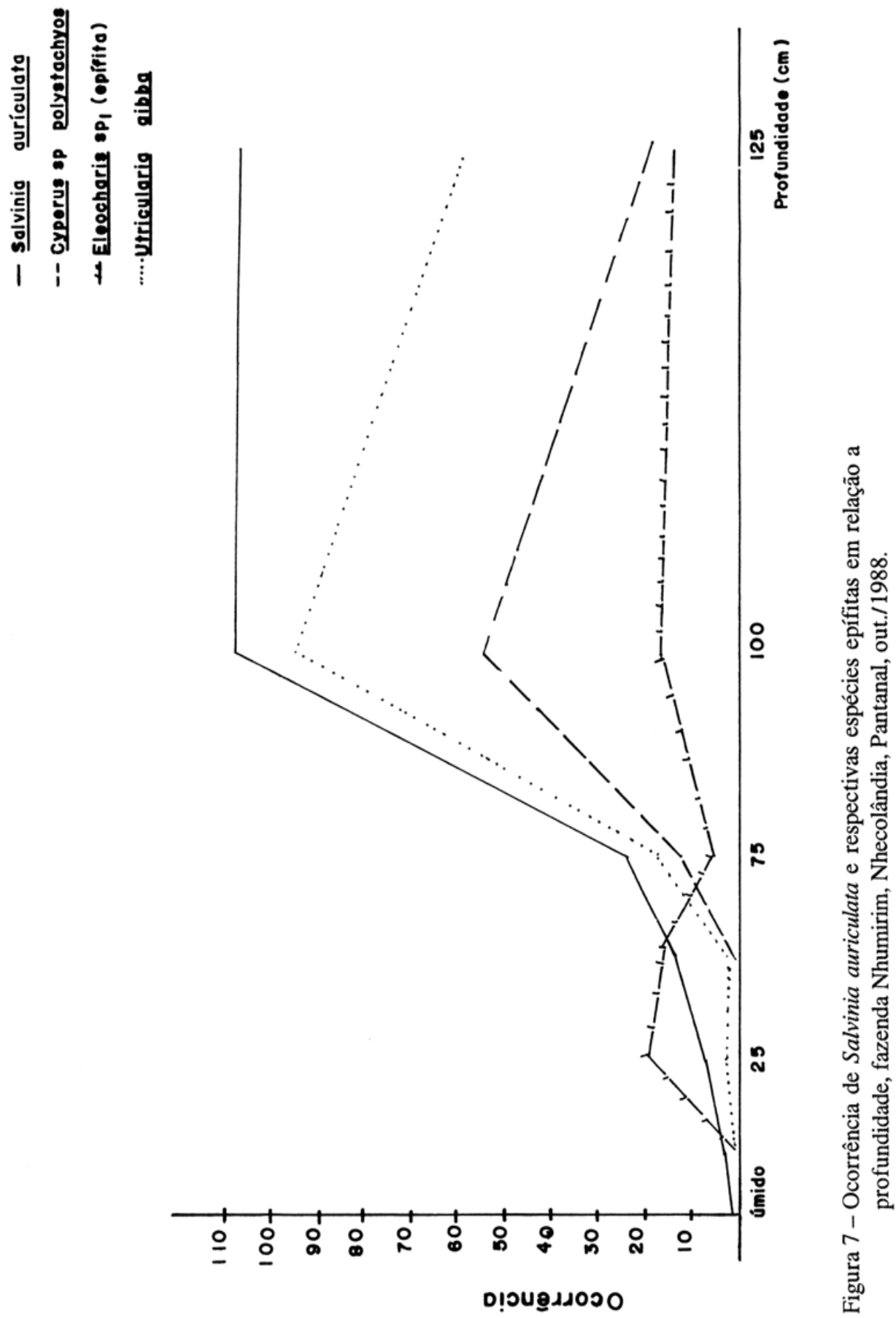


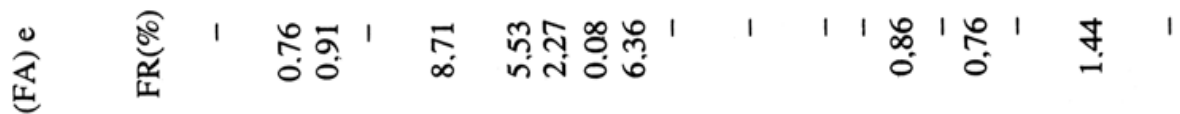

氶

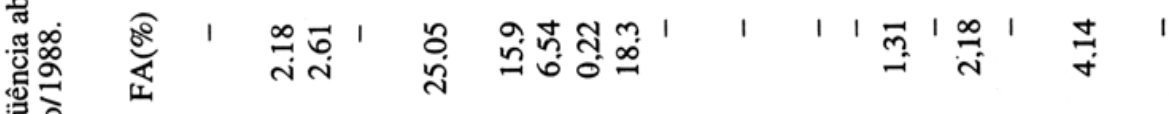

总郭

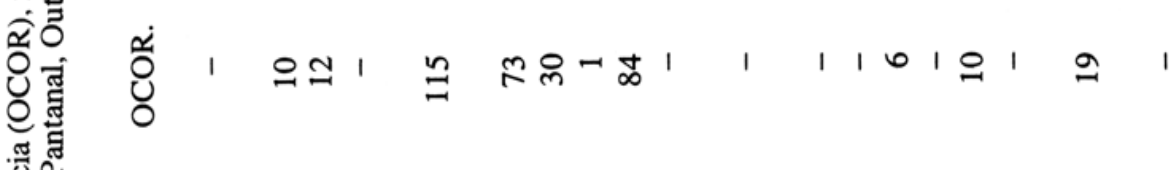

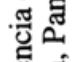

政.

s.

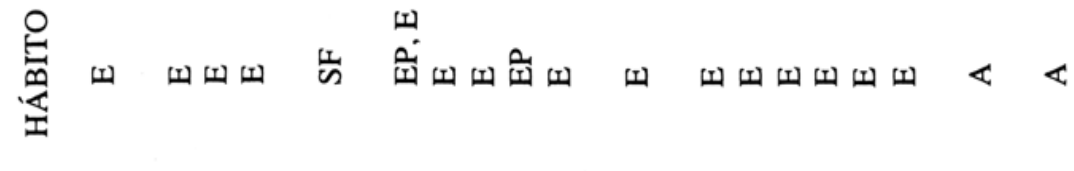

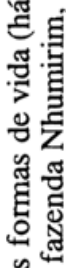

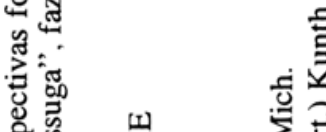

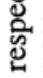

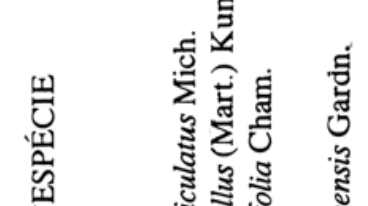

壾

ह.

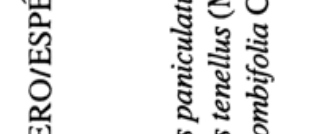

ชึ?

政

कू

离

की

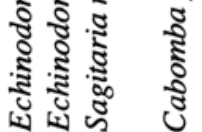

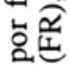

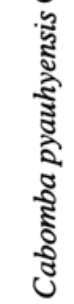

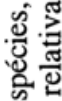

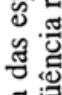

受总

焉

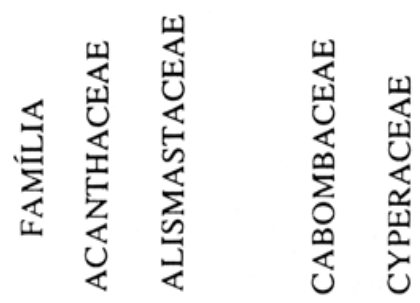

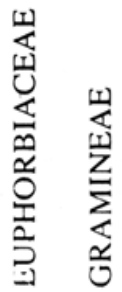

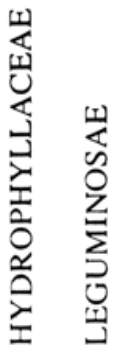


Distribuição de macrófitas aquáticas...

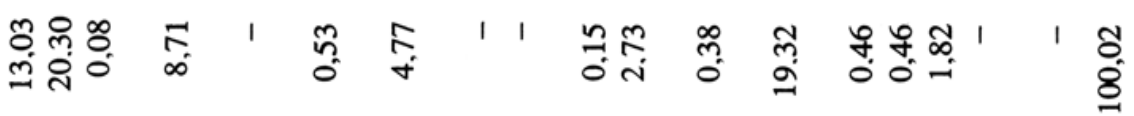

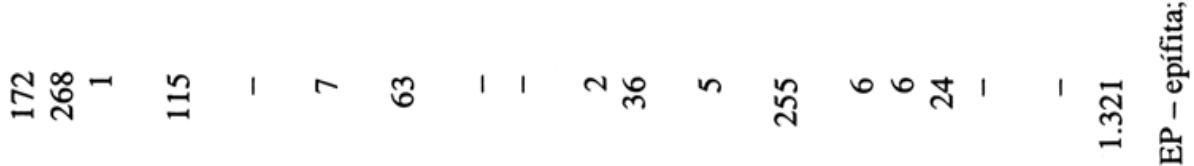

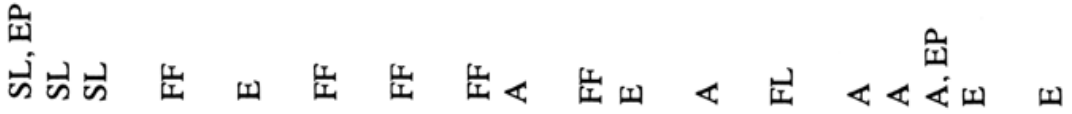

莺 这

ชี స

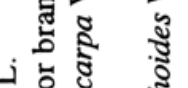

苟要

के के हे है

胥胥

㺃资

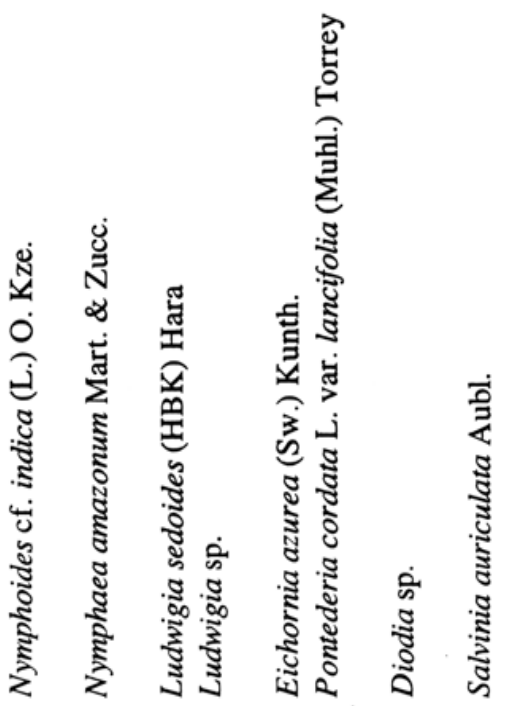

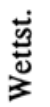

乐

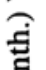

๓

通造

हิ่

ฐิ

हे के के

ป ถั

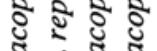

ह

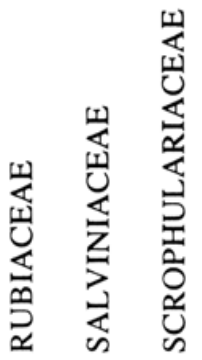

壳 
Tabela 2 - Ocorrência das espécies por faixa de profundidade (cm) na "Baía da Sanguessuga”, fazenda Nhumirim, Nhecolândia, Pantanal, outubro/1988.

\section{ESPÉCIES}

Bacopa myriophylloides

B. reptans

Bacopa sp. ${ }^{1}$

Diodia sp.

Hydrolea spinosa

Echinodorus tenellus

Eleocharis sp. ${ }^{2}$

Paspalidium paludivagum

Leersia hexandra

Pontederia cordata

Echinodorus paniculatus

Eleocharis sp. ${ }^{3}$

Eichornia azurea

Nymphoides $\mathrm{cf}$. indica

Nymphaea amazonum

Hydrocleis nymphoides

Utricularia hydrocarpa

Utricularia sp. 1

Salvinia auriculata

Eleocharis sp. 1

Utricularia gibba

Cyperus cf. polystachyos

Cabomba pyauhyensis $\begin{array}{lllllll}\text { HÁBITO } & \begin{array}{l}\text { BORBA } \\ \text { ÚMIDA }\end{array} & \text { P R O F U N D I D A D E (cm) } \\ & \text { 0 a 6(m) } & 1-25 & 26-50 & 51-75 & 76-100 & 101-125\end{array}$

A 6

A 6

$\begin{array}{lrlll}\text { A, EP } & 10 & 9 & 3 & 2\end{array}$

A

A

E

E

E

E

E

$\mathrm{E}$

E

FF

FF

FF

FF

SL

SL

FL

EP

$\mathrm{EP}, \mathrm{SL}$

EP

SF
2
5

6

20

2

33

$\begin{array}{lrr}3 & 16 & 17\end{array}$

$\begin{array}{ll}1 & 7 \\ & 1\end{array}$

$4 \quad 8$

$13 \quad 4 \quad 50$

$\begin{array}{llllll}1 & 1 & 9 & 32 & 30 & 42\end{array}$

1

$\begin{array}{lllll}17 & 31 & 34 & 41 & 146\end{array}$

$\begin{array}{rrrrrr}2 & 6 & 12 & 22 & 107 & 106 \\ 1 & 19 & 16 & 5 & 18 & 14\end{array}$

$\begin{array}{lllll}2 & 2 & 16 & 94 & 58\end{array}$

$11 \quad 54 \quad 19$

$15 \quad 100$ 